\title{
Evidence for protein and mRNA TSHr expression in fibroblasts from patients with thyroid-associated ophthalmopathy (TAO) after adipocytic differentiation
}

\author{
Patrizia Agretti, Giuseppina De Marco, Melissa De Servi, Claudio Marcocci, Paolo Vitti, Aldo Pinchera and \\ Massimo Tonacchera \\ Dipartimento di Endocrinologia e Metabolismo, Centro Eccellenza AmbiSEN Università di Pisa, Via Paradisa 2, 56124 Pisa, Italy \\ (Correspondence should be addressed to Massimo Tonacchera; Email: mtonacchera@hotmail.com)
}

\begin{abstract}
Objective: Thyroid-associated ophthalmopathy (TAO) is a chronic autoimmune disorder characterized by an increased volume of adipose/connective tissue in the human orbit.

Design: The aim of this study was to investigate the thyrotropin receptor (TSHr) expression in orbital fibroblasts from TAO patients undergoing adipocytic differentiation.

Methods: Retro-ocular tissue and skin were obtained from five patients undergoing orbital decompression surgery for TAO and placed in culture. Proliferating fibroblasts were subjected to adipocytic differentiation for 10 days. Total RNA was isolated from fibroblasts and was reverse transcribed. TSHr mRNA levels were determined by real-time PCR. cAMP was determined by radioimmunoassay (RIA) after fibroblast incubation with the substances to test.

Results: Orbital differentiated fibroblasts became rounded and acquired lipid droplets. The amount of TSHr mRNA in these fibroblasts was higher than fibroblasts not subjected to adipocytic differentiation. Immunocytochemical analysis showed TSHr protein in differentiated orbital fibroblasts. Differentiated orbital fibroblasts stimulated with bovine (b) TSH showed a cAMP production greater than that in paired undifferentiated cultures. A specific thyroid-inhibiting antibody (TBAb) inhibited cAMP production after bTSH challenge, and a thyroid-stimulating antibody (TSAb) stimulated cAMP production in differentiated fibroblasts.

Conclusions: We suggest that orbital fibroblasts subjected to adipocytic differentiation increase TSHr expression that responds specifically to bTSH and TSAb stimulation, and to TBAb inhibition.
\end{abstract}

European Journal of Endocrinology 152 777-784

\section{Introduction}

Thyroid-associated ophthalmopathy (TAO) is a chronic autoimmune disorder closely associated with Graves' disease $(1,2)$. Using computed tomography or magnetic resonance scans of the orbit, signs of TAO can be detected in up to $90 \%$ of the patients, but clinical features are evident in only $25-50 \%$ of patients with Graves' disease (2). The different clinical features of $\mathrm{TAO}$, which include proptosis, extraocular muscle dysfunction, periorbital edema and conjunctival injection, are due to inflammatory processes of retro-ocular tissues, leading to an increase in connective tissue and extraocular muscle volume (1). Histological examination of TAO revealed an accumulation of hydrophilic glycosaminoglycans and an increase in orbital adipose tissue (3). Fibroblasts of the connective orbital tissue are the major source of these glycosaminoglycans (4) and moreover, in appropriate in vitro culture conditions, may differentiate into mature adipocytes (5), potentially playing an important role in the development of
TAO. The close clinical association between immunogenic hyperthyroidism, ophthalmopathy and pretibial dermopathy suggests that the antigen involved in these conditions is shared among the thyroid gland, retro-ocular tissue and pretibial skin. The immune recognition event which causes the T lymphocytes' migration into the orbit has not yet been identified, and experimental evidence provides arguments both for and against it being the thyrotropin receptor (TSHr) (1, 6). Reports concerning the relationship between TSHr antibodies (TRAb) and the severity of ophthalmopathy are also controversial (7). Indeed, many patients with Graves' disease without clinically evident ophthalmopathy have high titers of TRAb in their serum (7). Conversely, some patients with severe TAO do not have detectable TRAb (7). In addition, there is no general agreement regarding the presence of the TSHr or its transcript in eye orbit structures. Some have found transcripts in retro-ocular fibroblasts (8) or inferred their presence in fat (9); others have failed to find a TSHr transcript in retro-ocular muscle 
also containing fibroblasts (10). A TSHr variant transcript comprising essentially exons $1-8$ was also described in many locations, including ocular muscle, fat, lymphocytes and fibroblasts (11). Recently, we have detected by real-time PCR similar levels of TSHr mRNA in TAO orbital tissues and extraorbital tissues from patients not affected by thyroid diseases (12). The expression and function of the TSHr in cultured rat preadipocytes are closely related to cellular differentiation (13), so fibroblasts of the human connective orbital tissue may be important in the development of TAO not only because they are the major source of glycosaminoglycans, but also because the are able to differentiate into mature adipocytes and increase the expression of a functional TSHr, the hypothetical common antigen in thyroid gland and retro-ocular tissue $(14,15)$.

Rosiglitazone, an agonist of peroxisome proliferatoractivated receptor $\gamma(\operatorname{PPAR} \gamma)$ is also able to induce adipocytic differentiation of the orbital fibroblasts and increase the TSHr expression (16).

In the present study we subjected human retroocular and skin fibroblasts from TAO patients to adipocytic differentiation conditions and we measured the absolute levels of TSHr mRNA by real-time PCR and TSHr protein expression by immunocytochemistry using a monoclonal antibody, we also assessed the TSHr functionality by meausuring extracellular cAMP accumulation after bovine (b) TSH stimulation.

\section{Materials and methods}

\section{Patients}

Retro-ocular tissue and orbital skin were obtained during orbital decompression surgery for severe TAO from five patients. The medium age of the patients was $25 \pm 4.6$ years old, three women and two men. The duration of the disease (appearance of hyperthyroidism and ophthalmopathy) was of 2 years in four patients and 3 years in the last patient. All of the patients were affected by persistent marked proptosis and two out of five patients were submmitted to intravenous glucocorticoids therapy 1 year before the decompression, while no patient was subjected to orbital radiotherapy. At surgery clinical activity score showed that only one patient had an active disease while in the remaining four patients only marked proptosis was present. The study was approved by the local ethical committee and written informed consent was obtained from all the subjects.

\section{Fibroblast cell culture}

Tissue samples were minced and placed directly in plastic culture dishes, allowing fibroblasts to proliferate in medium 199 containing 20\% fetal bovine serum (FBS), penicillin $(100 \mathrm{U} / \mathrm{ml})$ and gentamicin
$(20 \mu \mathrm{g} / \mathrm{ml})$, as described previously (17). Proliferating fibroblasts were sub-passaged in the same medium containing 10\% FBS and antibiotics.

\section{Adipocytic differentiation}

To start adipocytic differentiation, fibroblasts were grown to confluence and differentiation was carried out exactly as reported previously (15). Fibroblasts were also cultured for the same period of time in medium 199-10\% FBS without being switched to differentiation medium, as control.

\section{Oil Red $O$ staining}

Retro-ocular and skin fibroblasts were grown to confluence in 24-well plates and subjected to the adipocytic differentiation protocol or control conditions as described above. Cells were washed with phosphatebuffered saline (PBS), fixed with 10\% formalin for 30-60 min at room temperature (RT), incubated for $5 \mathrm{~min}$ with $60 \%$ isopropanol and stained for $5 \mathrm{~min}$ with Oil Red $\mathrm{O}$ solution $(1.8 \mathrm{mg} / \mathrm{ml})$. After rinsing with tap water, cells were counterstaind with Mayer's hematoxylin solution and observed under the phase contrast microscope.

\section{RNA isolation and reverse transcription}

Total RNA was isolated directly from the Petri dish-cultured fibroblasts using the TRIZOL reagent (Invitrogen Life Technologies, Carlsbad, CA, USA) according to the manufacturer's instructions. The quality of RNA samples was assessed by electrophoresis through denaturing agarose gel and staining with ethidium bromide to visualize the $18 \mathrm{~S}$ and $28 \mathrm{~S}$ RNA bands under UV illumination. The extraction yield was quantified spectrophotometrically at $260 \mathrm{~nm}$. One microgram of total RNA for each sample was reverse transcribed for $1 \mathrm{~h}$ at $42{ }^{\circ} \mathrm{C}$ in a $20 \mu \mathrm{l}$ reaction volume using 200 units of Superscript II Rnase $\mathrm{H}^{-}$reverse transcriptase (Invitrogen Life Technologies) in the presence of $1.5 \mu \mathrm{M}$ random examers (Pharmacia Biotech, Uppsala, Sweden), 0.01 M DTT and $1 \mathrm{mM}$ dNTP mix.

\section{Determination of TSHr mRNA levels using real-time PCR}

Oligonucleotide primers and TaqMan probes were designed to be intron-spanning, using the computer program Primer Express (Applied Biosystems, Foster City, CA, USA). To avoid amplification of contaminating genomic DNA, one of the two primers or the probe was placed at the junction between two exons, or in a different exon. The nucleotide sequence of the primers and probes (Applied Biosystems) are shown in Table 1. Quantitative PCR reactions were carried out on 96well optical reaction plates using a cDNA equivalent 
Table 1 Oligonucleotide sequence of the primers and the TaqMan hybridization probe for real-time PCR to quantitate TSHr cDNA.

Primer forward CCCGCTTACCGCCCAGT

Primer reverse

TAGAAAATGCATGACTTGGAATAGTTC

of $50 \mathrm{ng}$ total RNA for each sample in a volume of $50 \mu \mathrm{l}$ using the TaqMan Universal PCR Master Mix (Applied Biosystems) as described previously (12). To minimize errors arising from variations in the amount of starting RNA among samples, amplification of $\beta$-actin mRNA was performed as an internal reference against which other RNA values can be normalized. The primers and the probe for the $\beta$-actin RNA were purchased from Applied Biosystems and the amplification was started from $0.5 \mathrm{ng}$ total RNA. Normalized results were expressed as the ratio of the pg RNA of the TSHr gene to the pg RNA of the $\beta$-actin gene (mean \pm S.E. of three experiments).

\section{Immunocytochemical analysis of the TSHr protein}

Fibroblasts were seeded onto plastic chamber slides, grown to confluence as monolayers, and subjected to the differentiation protocol as described above. JPO9 cells were used as positive controls. The cells were washed with PBS and fixed in methanol for $15 \mathrm{~min}$ at $-20^{\circ} \mathrm{C}$. Non-specific background staining was blocked using Peroxide Block and Power Block (BioGenex, San Ramon, CA, USA) following the manifacturer's protocol. The monoclonal anti-TSHr antibody directed against the aminoacidic residues 211-414 at the 1:100 dilution (Novocastra Laboratories, Newcastle, UK) was applied overnight $(\mathrm{O} / \mathrm{N})$ at RT. Slides were washed with PBS, stained using the Super Sensitive Immunodetection Kit (BioGenex) as indicated by the manifacturer, and counterstained with Mayer's hematoxylin solution. Parallel slides with the primary antibody replaced by PBS were processed to asses the specificity of the system. Cells were examined at $\times 25$ and $\times 40$ magnification using an optical microscope.

\section{cAMP assay}

Fibroblasts seeding in 96-well plates were grown to confluence and the cAMP assay was performed. Cells were washed once with HBSS medium and incubated for an hour at $37^{\circ} \mathrm{C}$ in hypotonic medium containing $0.5 \mathrm{mM}$ IBMX as a cAMP phosphodiesterase inhibitor alone or togheter with the following substances to test: bTSH, forskolin, human recombinant follicular stimulating hormone (FSH), human recombinant chorionic gonadotropin ( $\beta \mathrm{hCG}$ ), a monoclonal anti-TSHr antibody (BA8; kindly gifted from S Costagliola), a thyroid inhibiting antibody (TBAb), a thyroid-stimulating antibody (TSAb), and a normal IgG. The TBAb was selected for its potent blocking activity on TSH action, while the TSAb was selected for its potent stimulating activity on the TSHr, evaluated by biological assay. $\mathrm{TBAb}$, TSAb and normal IgGs were extracted from the sera of patients with autoimmune thyroid diseases (Hashimoto's thyroiditis and Graves' disease, respectively) or from the sera of healthy subjects using the commercial kit Mab Trap G II (Pharmacia Biotech) according to the manifacturer's instructions. Extracellular cAMP was measured in the medium collected at the end of the incubation using an in house RIA assay with a commercial polyclonal anti-cAMP antibody, as previosly described (18), and expressed as pmoles per dish.

\section{Statistical analysis}

The expression of the TSHr mRNA detected in differentiated retro-ocular fibroblasts at passage 4, 12 and 22 from a representative patient with TAO was compared with its expression in retro-ocular fibroblasts not subjected to adipocytic differentiation using the Student test ( $t$-test); to test the significance, the risk level $(p)$ was set at 0.01 .

\section{Results}

\section{Adipocytic differentiation}

Confluent fibroblasts were subjected to differentiation protocol for 10 days and examined using phase contrast microscopy. Control cells were maintained for the same period of time in medium 199-10\% FBS. During the differentiation process retro-ocular fibroblasts from passage one to at least passage 11 lost their stellate shape and became rounded and oval (Fig. 1A) and lost their fibroblast-like aspect typical of the paired control cells (Fig. 1B). At the end of the differentiation period, about $5-10 \%$ of differentiated retro-ocular fibroblasts accumulated numerous lipid droplets within the cytoplasm (Fig. 2). The lipidic inclusions present in differentiated retro-ocular fibroblasts were positive to the fat-specific dye Oil Red $O$ (data not shown). The level of mRNA expression of adipocyte differention markers (leptin and PPAR $\gamma$ ), measured by real-time PCR, was also increased in retro-ocular fibroblasts subjected to adipocytic differentiation at early passages (data not shown). Skin fibroblasts subjected to adipocytic differentiation protocol were refractory to the effects imposed by the differentiation protocol, maintaining a stellate shape with broad, tapering cytoplasmic processes as paired control fibroblasts (Fig. 3A, 3B).

\section{Determination of TSHr mRNA levels}

To validate the real-time PCR method, a standard curve for the TSHr gene was constructed from cDNA obtained 
(A)

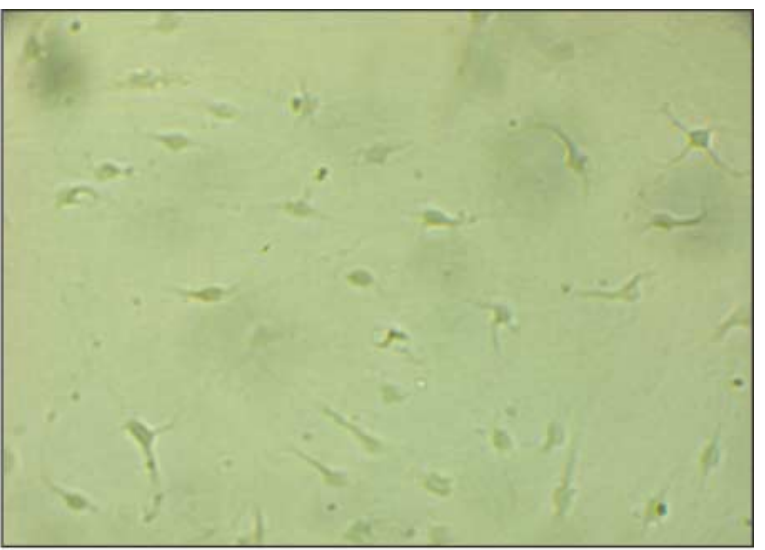

(B)

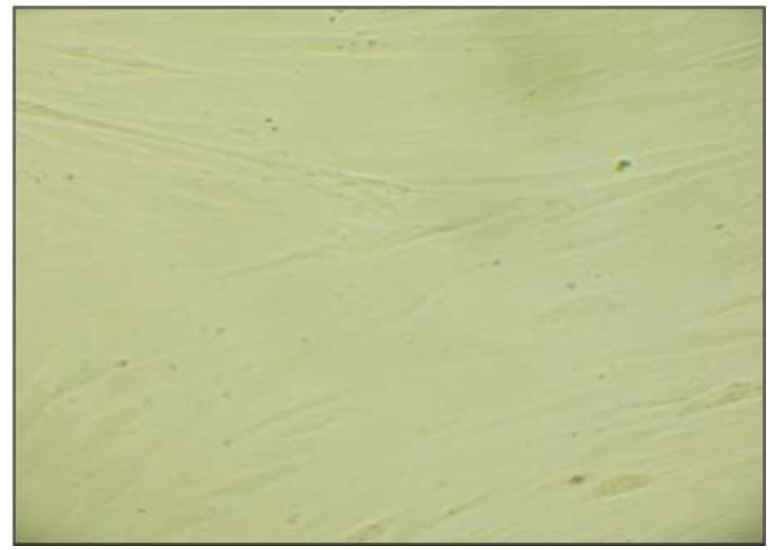

Figure 1 Retro-ocular fibroblasts at early passage (passage 4) from a representative TAO patient $(A)$ subjected and $(B)$ not subjected to adipocytic differentiation protocol observed by phase contrast microscopy ( $\times 10$ magnification). Many differentiated cells appeared round and oval, losing their fibroblast-like appearence.

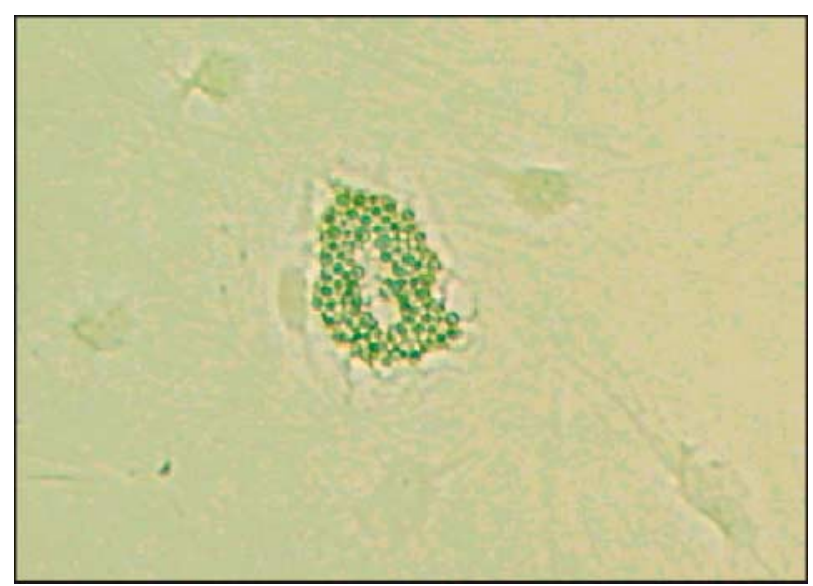

Figure 2 Retro-ocular fibroblasts at ealy passage cultured for 10 days in adipocytic differentiation medium observed by phase contrast microscopy ( $\times 10$ magnification). Morphological examination demonstrated enhanced adipogenesis in about $5-10 \%$ of the cells confirmed by the presence of numerous lipid inclusions inside the cytoplasm.
(A)

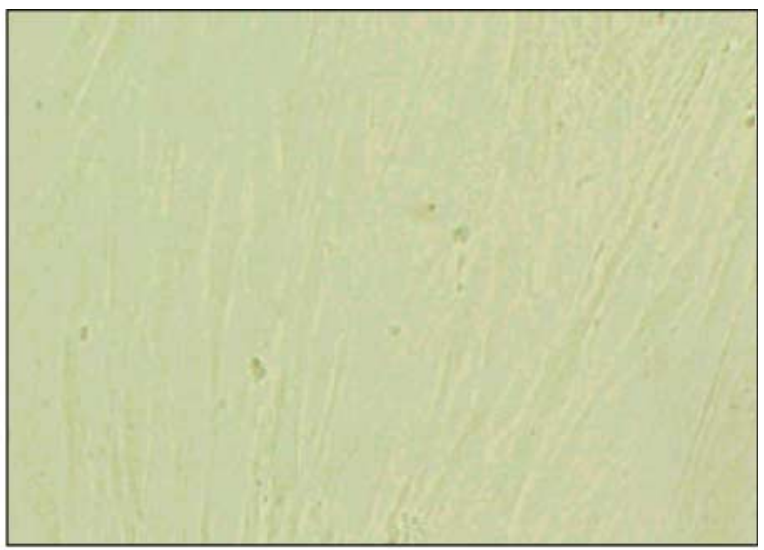

(B)

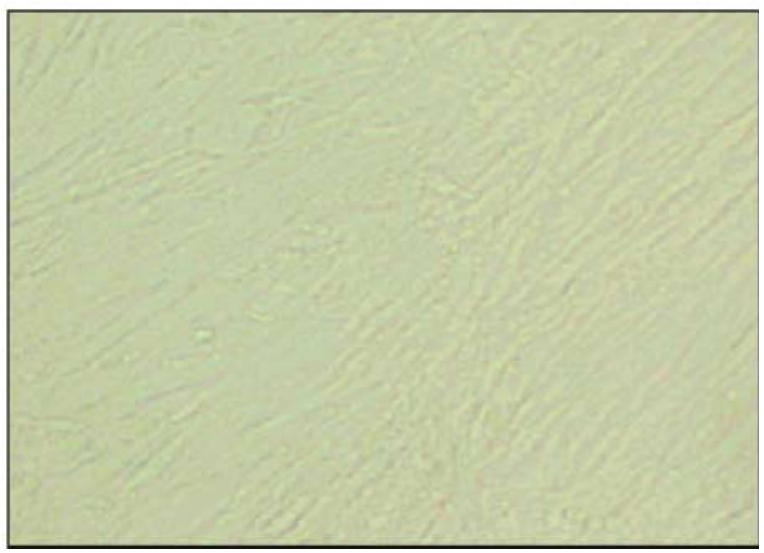

Figure 3 Skin fibroblasts at early passage (passage 4) from a representative TAO patient $(A)$ subjected and $(B)$ not subjected to adipocytic differentiation protocol observed by phase contrast microscopy ( $\times 10$ magnification). The cells maintained their tapered shape.

from normal thyroid tissue as described previously (12). A standard curve using the same cDNA was also constructed for the $\beta$-actin gene. For each experimental sample, the amount of the targets and the endogenous reference was determined from the standard curve. The target amount was divided by the endogenous reference amount to obtain a normalized target value. After normalization for the expression of the endogenous gene, the TSHr/ $\beta$-actin ratio, measured in retro-ocular fibroblasts subjected to adipocytic differentiation protocol, was about 17-fold higher than the value obtained for retro-ocular fibroblasts not subjected to adipocytic differentiation at passage 4 and about 32-fold higher at passage 12. No significant difference in TSHr mRNA expression was observed in differentiated and not differentiated retro-ocular fibroblasts at late passage (passage 22) (Table 2).

\section{Immunodetection of the TSHr protein}

The immunocytochemical analysis of the TSHr protein was performed using a commercial monoclonal antibody, as described in Materials and methods. 
Table 2 TSHr mRNA levels measured by real-time PCR in retro-ocular and skin fibroblasts from a representative TAO patient at culture passages 4, 12 and 22 subjected (differentiated) and not subjected (control) to adipocytic differentiation protocol. Each value represents the mean \pm S.E. of three independent experiments.

\begin{tabular}{lccc}
\hline & Passage 4 & Passage 12 & Passage 22 \\
\hline Differentiated skin fibroblasts & $0.750 \pm 0.2$ & $0.081 \pm 0.02$ & $0.0067 \pm 0.002$ \\
Control skin fibroblasts & $0.460 \pm 0.09$ & $0.030 \pm 0.009$ & $0.0025 \pm 0.001$ \\
Differentiated retro-ocular fibroblasts & $13.0 \pm 3.0^{*}$ & $18.0 \pm 4.0^{*}$ & $0.083 \pm 0.04$ \\
Control retro-ocular fibroblasts & $0.760 \pm 0.09$ & $0.560 \pm 0.08$ & $0.023 \pm 0.009$ \\
\hline
\end{tabular}

${ }^{*} P<0.01$.

Immunoreactivity for the TSHr protein was clearly detected in retro-ocular fibroblasts subjected to adipocytic differentiation protocol (Fig. 4A), while no staining was observed in the paired control cultures (Fig. 4B). Also retro-ocular fibroblasts subjected to adipocytic differentiation protocol processed without the primary antibody didn't show TSHr immunoreactivity (data not shown). Skin fibroblasts subjected and not subjected to adipocytic differentiation didn't show any TSHr-specific staining (data not shown). A very strong TSHr immunoreactivity was exibited by the positive control JPO9 cells (Fig. 4C), whereas the negative control represented by the JPO9 cells processed in the

(A)

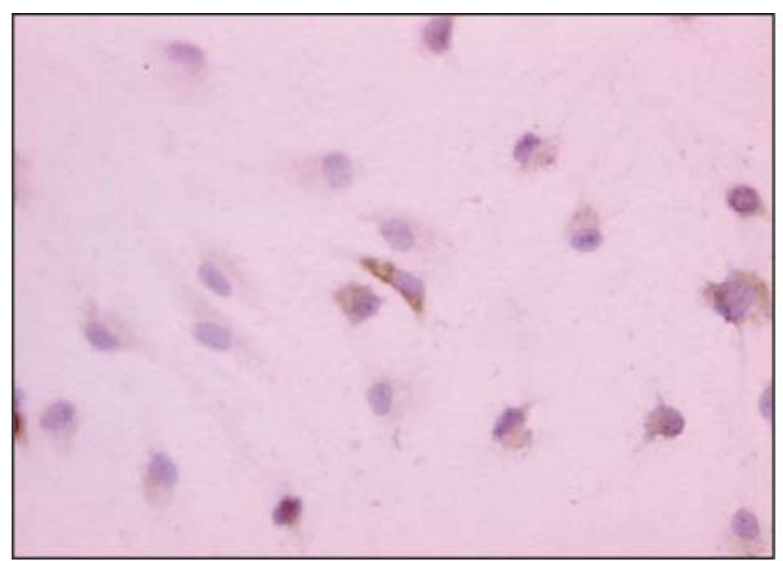

(C)

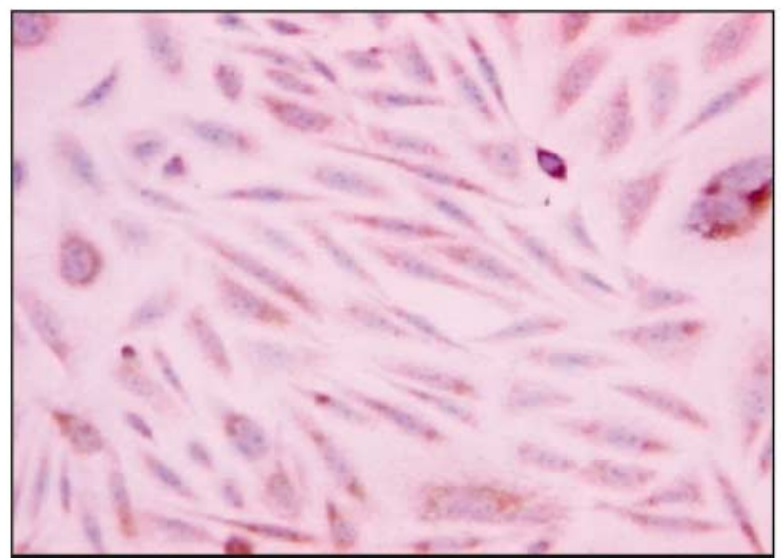

absence of the primary antibody showed no staining (Fig. 4D).

\section{cAMP measurement}

cAMP production was measured after bTSH stimulation in TAO retro-ocular and skin fibroblasts at different culture passages subjected and not subjected to adipocytic differentiation protocol. Increasing doses of bTSH $(0.1-100 \mathrm{mU} / \mathrm{ml})$ were able to stimulate cAMP production in differentiated retro-ocular fibroblasts at passage 3, 5 and 9, but this response to bTSH disappeared at passage 20 (Fig. 5). Retro-ocular fibroblasts

(B)

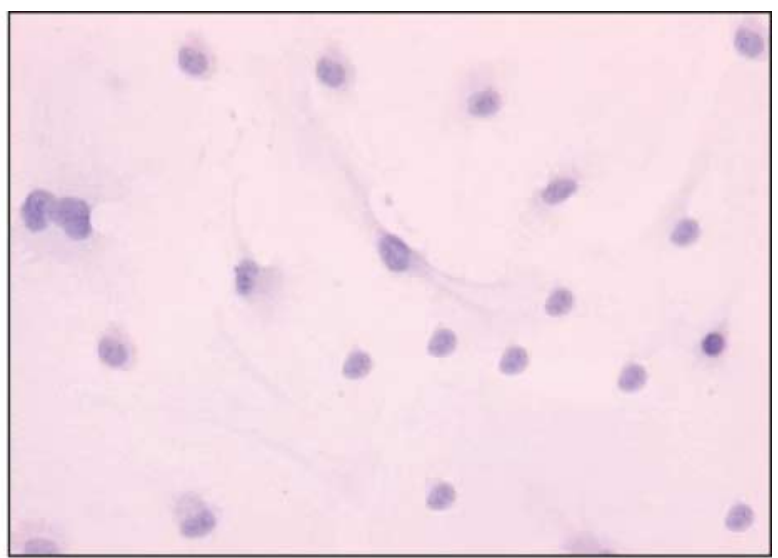

(D)

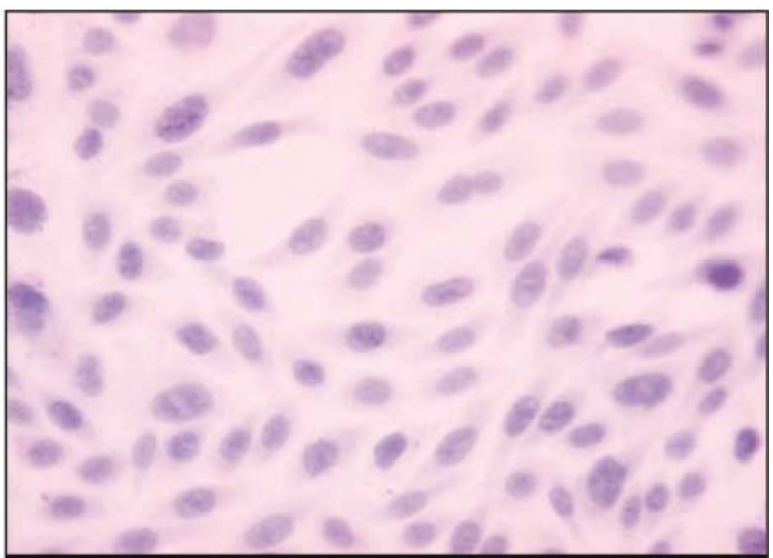

Figure $4 \mathrm{Immunodetection} \mathrm{of} \mathrm{the} \mathrm{TSHr} \mathrm{protein} \mathrm{using} \mathrm{a} \mathrm{commercial} \mathrm{monoclonal} \mathrm{antibody.} \mathrm{(A)} \mathrm{Differentiated} \mathrm{retro-ocular} \mathrm{fibroblasts,}$ (B) retro-ocular fibroblasts not subjected to adipocytic differentiation, (C) JPO9 cells, (D) JPO9 cells processed in the absence of the primary antibody. 


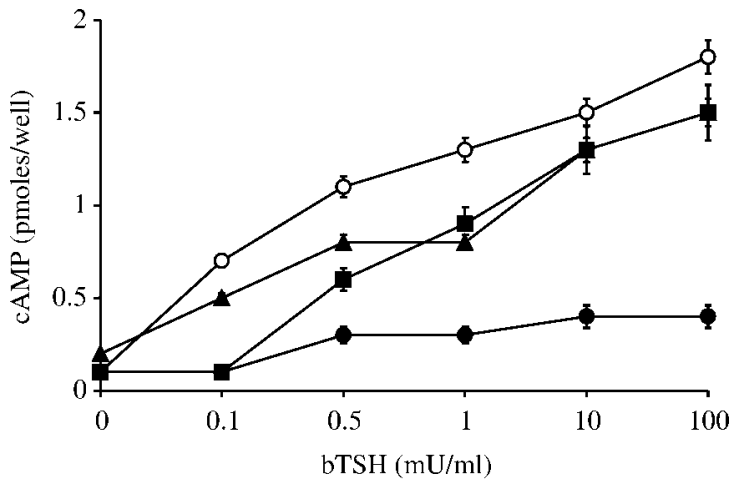

Figure 5 cAMP production after bTSH stimulation in retro-ocular fibroblasts from one representative patient subjected to adipocytic differentiation at different culture passages: $\bigcirc$, passage 3 ; $\boldsymbol{\Lambda}$, passage 5 ; $\mathbf{\square}$, passage 9 ; $\bullet$, passage 20 . Each point represents the mean \pm S.E. of three independent experiments. Where error bars are not visible, they are so small that they fall within the symbols.

not subjected to adipocytic differentiation and skin fibroblasts subjected and not subjected to adipocytic differentiation were not significatively stimulated by bTSH in terms of cAMP production (Fig. 6). cAMP production in differentiated retro-ocular fibroblasts was also stimulated by forskolin, while very high concentration of hrFSH and $\beta$ hCG were not able to increase cAMP production, suggesting a specific action of bTSH on its receptor (Fig. 7). The monoclonal antiTSHr antibody BA8 did not interfere with the bTSH action, while TBAb was able to abolish the bTSH stimulating effect (Fig. 7). TSAb increased the cAMP production to almost the same extent as $0.5 \mathrm{mU} / \mathrm{ml}$ bTSH, and no effect was shown by normal IgG (Fig. 7).

\section{Discussion}

The TSHr expressed on thyroid follicular cells is the autoantigen directly involved in the pathogenesis of

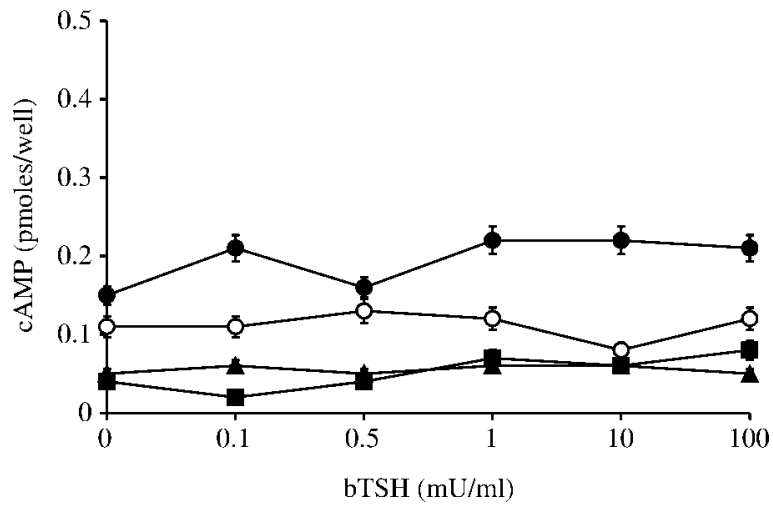

Figure 6 cAMP production after bTSH stimulation in skin fibroblasts from one representative patient subjected to adipocytic differentiation at different culture passages: $\bigcirc$, passage 3 ; $\mathbf{\Lambda}$, passage 5 ; passage 9 ; $\bullet$, passage 20 . Each point represents the mean \pm S.E. of three independent experiments. Where error bars are not visible, they are so small that they fall within the symbols.

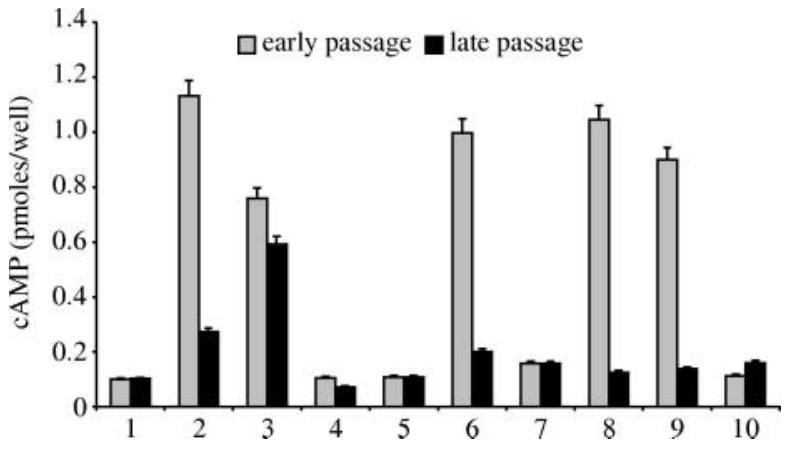

Figure 7 cAMP production in retro-ocular fibroblasts at early and late passages from a representative TAO patient subjected to adipocytic differentiation after one hour incubation at $37^{\circ} \mathrm{C}$ with: 1 , hypotonic buffer; 2 , bTSH $(0.5 \mathrm{mU} / \mathrm{ml}) ; 3$, forskolin $\left(10^{-5} \mathrm{M}\right)$; 4, FSH $(500 \mathrm{mU} / \mathrm{ml}) ; 5$, $\beta$ hCG $(5 \mathrm{mU} / \mathrm{ml}) ; 6$, BA8 plus bTSH $(0.5 \mathrm{mU} / \mathrm{ml}) ; 7$, TBAb $(1 \mathrm{mg} / \mathrm{ml})$ plus bTSH $(0.5 \mathrm{mU} / \mathrm{ml}) ; 8$, TSAb $(1 \mathrm{mg} / \mathrm{ml}) ; 9$, normal lgG $(1 \mathrm{mg} / \mathrm{ml})$ plus bTSH $(0.5 \mathrm{mU} / \mathrm{ml})$;

10 , normal $\operatorname{lgG}(1 \mathrm{mg} / \mathrm{ml})$. Each bar represents the mean \pm S.E. of three independent experiments. Where error bars are not visible, they are so small that they fall within the symbols.

Graves' disease, but whether this receptor is expressed in extrathyroidal tissues and if it participates directly in the pathogenesis of TAO is unclear $(1-3)$. The mechanisms that regulate the growth of orbital adipose tissue in thyroid associated ophthalmopathy remain unknown, but it has been demonstrated that a subset of orbital fibroblasts may be responsive to adipogenic signals (5).

The results obtained in this paper show that differentiated retro-ocular fibroblasts at early passages acquired an adipocyte-like shape and became rounded and oval with numerous lipid droplets within the cytoplasm at the end of the differentiation period. TSHr mRNA levels measured by real-time PCR in differentiated retro-ocular fibroblasts at early passages were about 20-fold higher compared with the values obtained for paired fibroblasts not subjected to adipocytic differentiation. This difference in TSHr mRNA expression disappeared when fibroblasts were used at late passages. Increasing doses of bTSH were able to stimulate cAMP production in retro-ocular fibroblasts subjected to adypocitic differentiation at early but not at late passages. TSAb was able to stimulate cAMP production in differentiated retro-ocular fibroblasts at early passages, while TBAb abolished the bTSH stimulatory effect. Immunoreactivity for the TSHr protein was detected in differentiated retro-ocular fibroblasts at early passages, but not in fibroblasts not subjected to adipocytic differentiation. These results were obtained from the fibroblasts of four out of five patients included in the study, while the fibroblasts obtained from the fifth patient did not show any significant increase in TSHr mRNA expression and in bTSH stimulated cAMP production, indicating a marked individual to individual variation in the behavior of retro-ocular fibroblasts from different TAO patients (15). The concept of 'preadipocyte' was described for the first time in 1973 by 
Poznanski et al. (19), defining a subpopulation of fibroblasts capable of undergoing adipocyte differentiation. Preadipocytes are able to evolve in mature adipose cells, modifying their gene expression profile $(20,21$, 22). The concept that adipose cells might express TSHr was formulated in 1964 by Rodbell (23) who demonstrated TSH stimulated lipolysis in rat epididymal cells showing for the first time extrathyroidal expression of the TSHr. Subsequent reports demonstrated specific TSH binding to guinea pig adipose and retro-ocular tissue (24) or to porcine orbital connective tissue membranes (25). In addition, guinea pig brown and white adipose tissues were shown to express TSHr mRNA (26). A functional TSHr was cloned from rat fat cells (27), and it has been demonstrated that the differentiation of rat preadipocytes is accompained by the expression of a functional TSHr (13). Oligonucleotide microarrays have also been used to confirm the patterns of gene expression in preadipocytes and adipocytes in vitro and in vivo. The TSHr has been shown to be highly expressed in adipocytes in vivo (28). Numerous results from several laboratories now suggest that the TSHr is expressed in various human extrathyroidal tissues $(29,30,31)$. The presence of the TSHr in human orbital tissue and orbital fibroblasts was demonstrated by using RT-PCR in $1993(8,9)$, but the possibility of an illegitimate transcription was raised $(32,33,34)$. In a previous report, we demonstrated by using a very sensitive and quantitative method such as real-time PCR that the levels of TSHr mRNA expressed in orbital tissues from TAO patients were similar to those obtained from tissues of patients not affected by thyroid diseases (12). Bahn et al. (35), by using liquid hybridization analysis, showed the presence of TSHr mRNA in the orbital adipose/connective tissue of TAO patients, but not in normal orbital tissue. Adipocytic differentiation of human orbital fibroblasts induces expression of functional thyrotropin receptor as demonstrated by the increase of cAMP production after rhTSH stimulation (15), and thyrotropin is able to stimulate TSHr expression in cultured orbital fibroblasts (14). Recently, Kumar et al. (36) reported an increased leptin, adiponectin, PPAR $\gamma$ and TSHr expression in the orbital tissues of patients with Graves' ophthalmopathy (GO) compared with normal orbital samples. In vitro differences in GO and normal preadipocytes resulted in enhanced adiponectin, leptin and TSHr expression, with greater expression of the two latter genes in the GO cultures (36). Recent data suggest a functional role of IgGs from patients with GO against the IGF-1 receptor (37). All of the data presented in this paper do not exclude a possible non-TSHr mediated effect from IgGs of patients with TAO.

In conclusion, we suggest that orbital fibroblasts subjected to adipocytic differentiation increase TSHr expression. This TSHr is able to respond specifically to bTSH and TSAb stimulation, and to TBAb inhibition.

\section{Acknowledgements}

This work was supported by the following grants: Ministero dell'Università e della Ricerca Scientifica (MURST), Programma di Ricerca: Le malattie della tiroide: dalle basi molecolari alla clinica. Ministero dell'Università e della Ricerca Scientifica (MURST), Programma di Ricerca: Strategie per la valutazione degli effetti disruptivi dei contaminanti ambientali sul sistema endocrino degli animali e dell'uomo. Ministero dell'Università e della Ricerca Scientifica (MURST), Programma di Ricerca: Oftalmopatia basedowiana: analisi dei fattori patogenetici, nuovi approcci diagnostici e terapeutici, efficacia e potenziali rischi a lungo termine dei trattamenti tradizionali.

\section{References}

1 Bahn RS \& Heufelder AE. Pathogenesis of Graves' ophthalmopathy. New England Journal of Medicine 199311 1468-1474.

2 Marcocci C, Bartalena L, Bogazzi F, Panicucci M \& Pinchera A. Studies on the occurrence of ophthalmopathy in Graves' disease. Acta Endocrinologica 1989120 473-478.

3 Hufnagel TJ, Hickey WF, Cobbs WH, Jakobiec FA, Iwamoto T \& Eagle RC. Immunohistochemical and ultrastructural studies on the exenterated orbital tissues of a patient with Graves' disease. Ophthalmology 198491 1411-1414.

4 Smith TJ, Bahn RS \& Gorman CA. Connective tissue, glycosaminoglycans, and diseases of the thyroid. Endocrine Review 198910 366-391.

5 Sorisky A, Pardasani D, Gagnon A \& Smith TJ. Evidence of adipocyte differentiation in human orbital fibroblasts in primary culture. Journal of Clinical Endocrinology and Metabolism 1996 $813428-3431$.

6 Paschke R, Vassart G \& Ludgate M. Current evidence for and against the TSH receptor being the common antigen in Graves' disease and thyroid associated ophthalmopathy. Clinical Endocrinology $1995 \mathbf{4 2} 565-569$.

7 Rapoport B, Chazenbalk GD, Juame JC \& McLachlan SM. The thyrotropin receptor: interaction with TSH and autoantibodies. Endocrine Review 199819 673-716.

8 Heufelder AE, Dutton CM, Sarkar G, Donovan KA \& Bahn RS. Detection of TSH receptor RNA in cultured fibroblasts from patients with Graves' ophthalmopathy and pretibial dermopathy. Thyroid 19933 297-300.

9 Feliciello A, Porcellini A, Ciullo I, Bonavolontà G, Avvedimento EV \& Fenzi G. Expression of thyrotropin receptor mRNA in healthy and Graves' disease retro-orbital tissue. Lancet $1993 \mathbf{3 4 2}$ 337-338.

10 Paschke R, Elisei R, Vassart G \& Ludgate M. Lack of evidence supporting the presence of mRNA for the thyrotropin receptor in extra-ocular muscle. Journal of Endocrinological Investigation $199316329-332$.

11 Paschke R, Metcalfe A, Alcade L, Vassart G, Weetman A \& Ludgate M. Presence of nonfunctional thyrotropin receptor variant transcripts in retroocular and other tissues. Journal of Clinical Endocrinology and Metabolism 199479 1234-1238.

12 Agretti P, Chiovato L, De Marco G, Marcocci C, Mazzi B, SellariFranceschini S, Vitti P, Pinchera A \& Tonacchera M. Real-time PCR provides evidence for thyrotropin receptor mRNA expression in orbital as well as in extraorbital tissues. European Journal of Endocrinology 2002147 733-739.

13 Haraguchi K, Shimura H, Lin L, Endo T \& Onaya T. Differentiation of rat preadipocytes is accompained by expression of thyrotropin receptors. Endocrinology $19961373200-3205$. 
14 Bahn RS, Dutton CM, Natt J, Joba W \& Heufelder AE. Thyrotropin receptor expression in cultured Graves' preadipocyte fibroblasts is stimulated by thyrotropin. Thyroid $1998 \mathbf{8} 193-196$.

15 Valyasevi RW, Erickson DZ, Harteneck DA, Dutton CM, Heufelder AE, Jyonouchi SC \& Bahn RS. Differentiation of human orbital preadipocyte fibroblasts induces expression of functional thyrotropin receptor. Journal of Clinical Endocrinology and Metabolism 199984 2557-2562.

16 Valyasevi RW, Harteneck D, Dutton CM \& Bahn RS. Stimulation of adipogenesis, peroxisome proliferator-activated receptor- $\gamma$, and thyrotropin receptor by PPAR $\gamma$ agonist in human orbital preadipocyte fibroblasts. Journal of Clinical Endocrinology and Metabolism $2002872352-2358$.

17 Bahn RS, Gorman CA, Woloschak GE, David CS, Johnson PM \& Johnson CM. Human retroocular fibroblasts in vitro: a model for the study of Graves' ophthalmopathy. Journal of Clinical Endocrinology and Metabolism 198765 665-670.

18 Vitti P, Chiovato L, Ceccarelli P, Lombardi A, Novaes M Jr, Fenzi GF \& Pinchera A. Thyroid-stimulating antibody mimics thyrotropin in its ability to desensitize the adenosine $3^{\prime}, 5^{\prime}$-monophosphate response to acute stimulation in continuously cultured rat thyroid cells (FRTL5). Journal of Clinical Endocrinology and Metabolism $198663454-458$.

19 Poznanski WJ, Waheed I \& Van R. Human fat cell preculsors. Laboratory Investigation 197329 570-576.

20 Van RLR, Bayliss CE \& Roncari DAK. Cytological and enzymological characterization of adult human adipocyte precursors in culture. Journal of Clinical Investigation $1976 \mathbf{5 8} 699-704$.

21 Hauner H, Entenmann G, Wabitsch M, Gaillard D \& Ailhaud G. Promoting effects of glucocorticoids on the differentiation of human adipocyte preculsor cells cultured in a chemically defined medium. Journal of Clinical Investigation 198984 1663-1670.

22 Erickson DZ, Harteneck DA, Erickson BJ, Dutton CM \& Bahn RS Induction of leptin expression in orbital preadipocyte fibroblasts. Thyroid $200111221-226$.

23 Rodbell M. Metabolism of isolated fat cells. I. Effects of hormones on glucose metabolism and lipolysis. Journal of Biological Chemistry 1964239 375-380.

24 Davies TF, Teng CS, McLachlan SM, Smith BR \& Hall R. Thyrotropin receptors in adipose tissue, retro-orbital tissue and lymphocytes. Molecular and Cellular Endocrinology 19789 303-310.

25 Perros P \& Kendall-Taylor P. Demonstration of thyrotropin binding sites in orbital connective tissue: possible role in the pathogenesis of thyroid-associated ophthalmopathy. Journal of Endocrinological Investigation 199417 163-170.

26 Roselli-Rehfuss L, Robbins LS \& Cone RD. Thyrotropin receptor messenger ribonucleic acid is expressed in most brown and white adipose tissues in guinea pig. Endocrinology 1992130 $1857-1861$.

27 Endo T, Ohta K, Haraguchi K \& Onaya T. Cloning and functional expression of thyrotropin receptor cDNA from rat fat cells. Journal of Biological Chemistry 1994270 10833-10837.

28 Soukas A, Socci ND, Saatkamp BD, Novelli S \& Friedman JM. Distinct transcriptional profiles of adipogenesis in vivo and in vitro. Journal of Biological Chemistry 2001276 34167-34174.

29 Endo T, Ohno M, Kotani S, Gunjik K \& Onaya T. Thyrotropin receptor in non-thyroid tissues. Biochemical and Biophysical Research Communications 1993190 774-779.

30 Hiromatsu Y, Sato M, Inoue Y, Koga M, Miyake I, Kameo J, Tokisawa S, Yangg D \& Nonaka K. Localization and clinical significance of thyrotropin receptor mRNA expression in orbital fat and eye muscle tissues from patients with thyroid-associated ophthalmopathy. Thyroid $1996 \mathbf{6} 553-562$.

31 Stadlmair W, Spitzweg C, Bichlmair AM \& Heufelder AE. Full lenght TSH receptor transcripts and TSH receptor-like immunoreactivity in orbital and pretibial fribroblasts of patients with Graves' ophthalmopathy and pretibial dermopathy. Thyroid $199773-12$.

32 Chelly J, Concordet JP, Kaplan JC \& Kahan A. Illegitimate transcription: transcription of any gene in any cell type. PNAS 1989 $862617-2621$.

33 Crisp MS, Lane C, Halliwell M, Wynford-Thomas D \& Ludgate M. Thyrotropin receptor transcripts in human adipose tissue. Journal of Clinical Endocrinology and Metabolism 199782 2003-2005.

34 McGregor AM. Has the target for Graves' ophthalmopathy been found? Lancet $1998352595-596$.

35 Bahn RS, Dutton CM, Natt J, Joba W, Spitzweg C \& Heufelder AE. Thyrotropin receptor expression in Graves' orbital adipose/connective tissue: potential autoantigen in Graves' ophthalmopathy. Journal of Clinical Endocrinology and Metabolism $1998 \mathbf{8 3}$ 998-1002.

36 Kumar S, Coenen MJ, Scherer PE \& Bahn RS. Evidence for enhanced adipogenesis in the orbits of patients with Graves' ophthalmopathy. Journal of Clinical Endocrinology and Metabolism 200489 930-935.

37 Pritchard J, Han R, Horst N, Cruikshank WW \& Smith TJ. Immunoglobulin activation of $\mathrm{T}$ cell chemoattractant expression in fibroblasts from patients with Graves' disease is mediated through the insulin-like growth factor I receptor pathway. The Journal of Immunology $20031706348-6354$.

Received 10 November 2004

Accepted 26 January 2005 